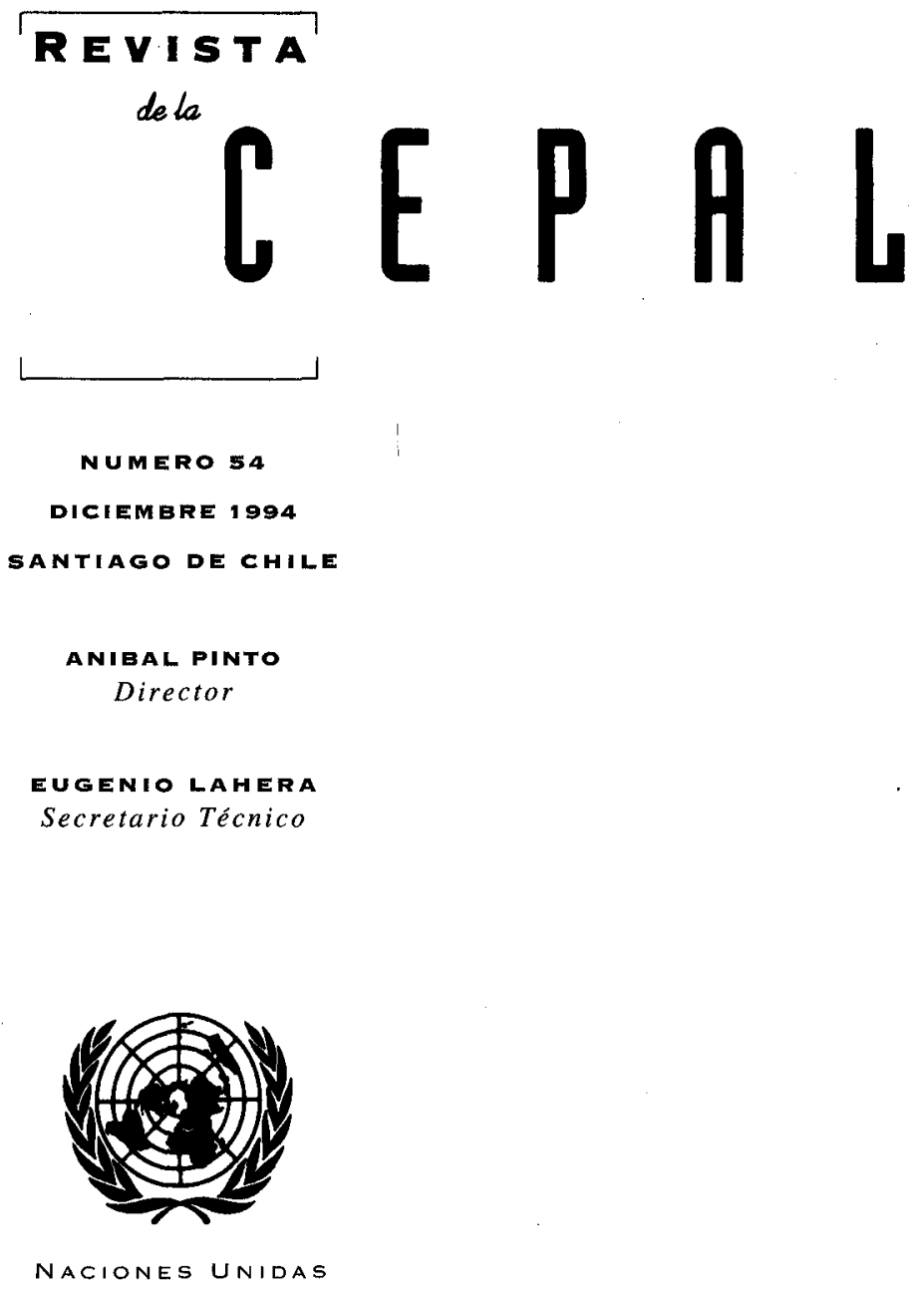


Mercados de salud: morfología, comportamiento y regulación

Jorge Katz y Ernesto Miranda

¿Liberalización o desarrollo financiero?

Günther Held

Ajuste fiscal y gasto social

Rossella Cominetti

Logros y obstáculos en la educación formal de las mujeres

Diane Alméras

¿Qué se entiende por flexibilidad del mercado de trabajo?

Ricardo A. Lagos

Modernización de la supervisión bancaria

Christian Larraín

Costos y beneficios de la integración centroamericana

Luis Cáceres

Algunas enseñanzas de las privatizaciones en Argentina

Daniel Azpiazu y Adolfo Vispo

Ventajas comparativas extraordinarias y crecimiento a largo plazo:

el caso de Ecuador

André A. Hofman y Rudolf Buitelaar

Industria cultural y nuevos códigos de modernidad

Martín Hopenhayn

Orientaciones para los colaboradores de la Revista de la CEPAL

Publicaciones recientes de la CEPAL 


\section{Costos y beneficios de la integración centroamericana}

\section{Luis René Cáceres}

Oficial Principal,

Departamento de

Planificación Estratégica y

Política Operativa, Banco

Interamericano de

Desarrollo
Este artículo reseña los beneficios y los costos de la integración económica centroamericana. El aumento del crecimiento económico, la industrialización basada en el comercio intraindustrial y la mayor competencia en un mercado ampliado a una escala subregional representan significativos beneficios para los países centroamericanos. Sin embargo, los beneficios están concentrados principalmente en los países de mayor desarrollo relativo. Los costos provienen de los flujos monetarios entre países por el arbitraje de monedas, por el fenómeno de sustitución de monedas, y por los altos costos de transacción asociados a la inconvertibilidad cambiaria. La eliminación de estos costos tendría otros en términos de merma de la autonomía nacional en la conducción de las políticas macroeconómicas, a raíz de la coordinación y seguimiento multilaterales. El artículo concluye con un llamado a establecer esquemas de coordinación que vayan más allá de las políticas macroeconómicas, para abarcar una agenda regional de transformación estructural y orientar el esfuerzo regional hacia una armonización de políticas que elimine disparidades y vuelva a los países centroamericanos más integrables entre sí y con la economía internacional. 


\section{I}

\section{Introducción}

En los últimos tres años, el proceso de integración económica centroamericana ha mostrado avances apreciables: la etapa de estancamiento que prevaleció en los años ochenta se ha revertido. El comercio intracentroamericano ha mantenido una tendencia ascendente desde 1986 y, en 1992, alcanzó a 892 millones de dólares, suma cercana al máximo valor histórico registrado en 1980. Esto puede explicarse por el crecimiento económico experimentado en los países de la zona, la mejoría de su liquidez externa y sus significativos avances en la eliminación de barreras al comercio. ${ }^{l}$ En materia institucional, los logros también han sido significativos. Sobresalen el inicio de las funciones de la Secretaría del Sistema de Integración Centroamericana (SICA); la incorporación de Nicaragua al Parlamento Centroamericano; el establecimiento de acuerdos de comercio e inversión entre la subregión y México, Venezuela y Colombia; los avances en la coordinación de políticas económicas, y la aprobación por los presidentes centroamericanos del Protocolo al Tratado General de Integración Económica Centroamericana. Todos estos logros constituyen un presagio optimista de que la integración centroamericana ha entrado en una nueva etapa que puede ser de grandes realizaciones.
No obstante lo expuesto, todavía hay mucho por hacer para lograr una integración plena. De hecho, las exportaciones recíprocas entre Guatemala y $\mathrm{El}$ Salvador representan 59\% del comercio intrasubregional total. Además, en 1992, el comercio extrasubregional acusó valores inferiores a los que prevalecieron en 1980 en todos los países, con excepción de Costa Rica. Por otra parte, las necesidades de inversión en infraestructura física son cuantiosas y considerables los rezagos de los sectores sociales en algunos países.

Los importantes avances que se han logrado en años recientes, así como la globalización económica, y la entrada en vigor del Tratado de Libre Comercio entre México, Estados Unidos y Canadá (TLC) hacen oportuno examinar cuáles son los aportes que la integración ofrece a las economías centroamericanas. En las páginas siguientes se pasa revista a los beneficios que las economías centroamericanas podrían obtener de la integración (sección II), se identifican algunos obstáculos que han inhibido la concreción de esos beneficios potenciales (sección III), se discuten los posibles costos de la integración - y de la no integración - y se proponen esquemas de coordinación y armonización de políticas que minimizarían tales costos (sección IV), y por último, se presenta un conjunto de conclusiones (sección V).

\section{II}

\section{¿Qué beneficios aportaría la integración?}

\section{Ahorro interno}

Un beneficio potencial es el aumento del ahorro interno como resultado del incremento de las exportaciones intrasubrregionales, dada la relación causal en-

\footnotetext{
$\square \mathrm{El}$ autor agradece los comentarios de Iris Alvarez, Claudio Ansorena, Florencio Ballestero, Gilbero Chona, Uziel Nogueira, Oscar Núñez Sandoval, Luis Amado Sánchez y Gabriel Siri. Los puntos de vista expuestos en este trabajo son de responsabilidad exclusiva del autor.

1 Sobre la evolución reciente de la integración centroamericana, véase CEPAL (1993).
}

tre las exportaciones y el ahorro en los países en desarrollo (J.K. Lee, 1971; Laumas, 1982). Con datos anuales correspondientes al período 1971-1988, se estimaron ecuaciones para el ahorro interno (S) en función de las exportaciones hacia afuera de Centroamérica $\left(\mathrm{X}_{\mathrm{o}}\right)$ y hacia Centroamérica $\left(\mathrm{X}_{\mathrm{CA}}\right)$, así como para el ingreso interno bruto menos las exportaciones totales (Y-X). Los resultados se muestran en el cuadro 1.

Puede apreciarse que el principal determinante del ahorro nacional son las exportaciones extrasubregionales. El coeficiente de las exportaciones hacia Centroamérica tiene signo negativo y estadísticamen- 
CUADRO 1

Centroamérica: Ahorro y exportaciones a

\begin{tabular}{|c|c|c|c|}
\hline & Ecuación & $\mathrm{R}^{2}$ & DW \\
\hline Guatemala & $\begin{array}{l}55.5801 \\
(1.97)\end{array}$ & 0.98 & 1.53 \\
\hline El Salvador & $\begin{array}{lll}99.5437 & -0.1915(\mathrm{Y}-\mathrm{X}) & 0.8159 \mathrm{X}_{\mathrm{O}}+0.5554 \mathrm{X}_{\mathrm{CA}} \\
(1.99) & (5.65) & 0.010)\end{array}$ & 0.87 & 2.16 \\
\hline Honduras & $\begin{array}{ccc}-17.8749 & -0.0285(\mathrm{Y}-\mathrm{X}) & 0.5649 \mathrm{X}_{\mathrm{O}}+0.5715 \mathrm{X}_{\mathrm{CA}} \\
(0.57) & (0.94) & (6.23)\end{array}$ & 0.91 & 1.33 \\
\hline Costa Rica & $\begin{array}{ccc}-101.4822+0.0192(\mathrm{Y}-\mathrm{X}) & +1.00 \mathrm{X}_{\mathrm{O}}-0.9359 \mathrm{X}_{\mathrm{CA}} \\
(2.61) & (0.64) & (11.77)\end{array}$ & 0.96 & 2.02 \\
\hline
\end{tabular}

Fuente: SIECA, Estadísticas macroeconómicas de Centroamérica, Guatemala, varios números. La serie de datos para Nicaragua estaba incompleta.

a Los valores estadísticos " $t$ " se muestran debajo de los correspondientes coeficientes; $R$ y DW denotan, respectivamente, el coeficiente de determinación y el coeficiente Durbin-Watson.

te significativo en Guatemala y Costa Rica, y uno positivo y no significativo en El Salvador. De esa manera, se aprecia que las exportaciones intrarregionales no estimulan el ahorro, excepto en Honduras. Esto puede explicarse por el hecho de que una gran parte del comercio intrasubrregional está constituido por bienes de consumo que, para su fabricación, requieren la importación de bienes intermedios (Cáceres y Quintanilla, 1990).

\section{Creación de comercio}

Una posible ventaja de la integración es la prevalencia de la creación de comercio sobre la desviación de comercio en el intercambio intrasubregional. La creación de comercio ocurre cuando la producción interna es desplazada por importaciones más baratas provenientes de los países miembros. La desviación de comercio tiene lugar cuando la producción relativamente barata de un país no miembro del esquema de integración es reemplazada por la producción más cara de un país miembro. La medición de la creación y la desviación de comercio se basa en que, sin integración, la elasticidad del ingreso de las importaciones totales permanece constante. Cuando esta elasticidad aumenta en el período posterior a la integración se deduce que ha habido creación de comercio.

A fin de detectar este fenómeno se estimó para Honduras, durante el período 1950-1969, una ecuación que expresa las importaciones totales (M) en función del producto nacional bruto $(\mathrm{Y})$, una variable ficticia (W) que permite detectar el cambio en el coeficiente del ingreso en el período posintegración 1962-1969 y el tiempo (T):

$\log M=-6.6249+1.8393 \log Y-0.0157 W-0.0251 T \quad R^{2}=0.97$
(3.18) (5.37)
$(0.53)$
(2.88)
$\mathrm{DW}=1.68$

$\mathrm{El}$ hecho de que la variable $\mathrm{W}$ no sea estadísticamente significativa indica que la elasticidad-ingreso de las importaciones no experimentó cambio. Por tanto, en Honduras no hubo creación ni desviación de comercio. Un resultado similar se obtuvo cuando se estimó la ecuación para el período 1970-1991 y se trató de detectar un cambio de la elasticidad-ingreso en el período 1986-1991 a través de la variable W':

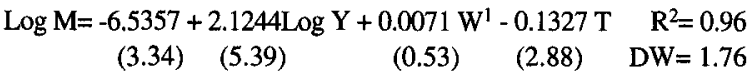

En las ecuaciones estimadas para los demás países en el período 1962-1991 (cuadro 2), W1 y W2 muestran los cambios en el coeficiente de Log Y en los años setenta y ochenta, respectivamente. Se puede apreciar en ellas que, salvo en El Salvador, las variables ficticias no son significativas.

Lo anterior indica que la integración no condujo a un cambio en la asignación de recursos en los períodos anterior y posterior a la integración, excepto en El Salvador. El caso de este país se podría explicar por el hecho de que el comercio intrasubregional sí representa un alto porcentaje de sus exportaciones totales, lo cual — según Balassa, 1967 - es condición para que haya creación de comercio. 
CUADRO 2

Centroamérica (tres países): Cambio en la propensión marginal a importar

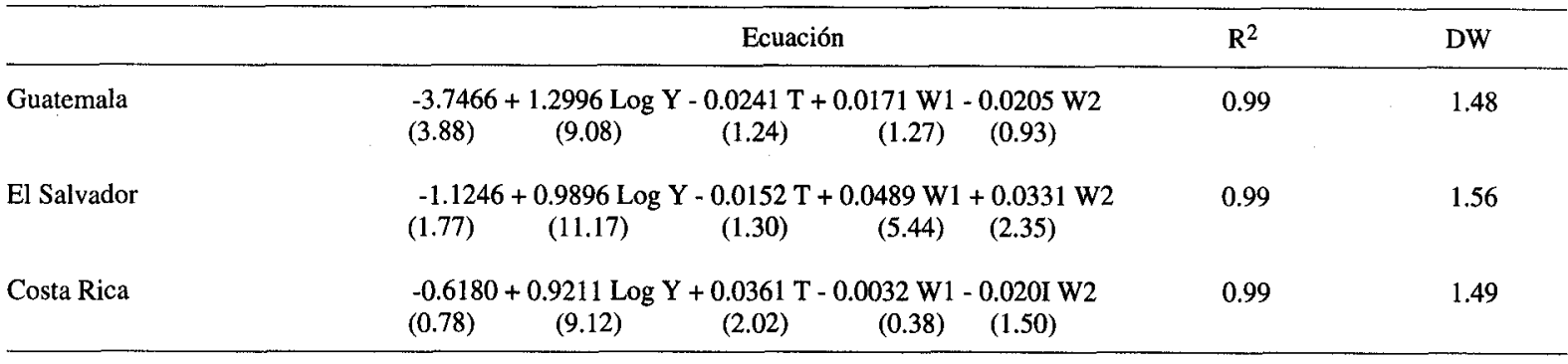

Fuente: Fondo Monetario Internacional (FMI), Estadísticas financieras internacionales. Anuario 1993, vol. XLVI, Washington, D.C., 1993.

\section{Incremento del crecimiento económico}

La integración da lugar a un "desparrame" de impulsos de crecimiento económico entre los países miembros, a través de las corrientes comerciales recíprocas. Estudios efectuados muestran que la magnitud de estos impulsos es considerable, pero que en Centroamérica varía mucho de un país a otro (Nugent, 1974; Cáceres, 1981; Cáceres y Seninger, 1980). Una cuantificación de ese efecto puede obtenerse a través del modelo siguiente:

$$
\begin{array}{ll}
\text { País 1 } & \text { País 2 } \\
\mathrm{C}_{\mathrm{P} 1=\left(1-\mathrm{s}_{1}\right) \mathrm{Y}_{1}} & \mathrm{C}_{\mathrm{P} 2}=\left(1-\mathrm{s}_{2}\right) \mathrm{Y}_{2} \\
\mathrm{I}_{1}=\mathrm{b}_{1} \mathrm{Y}_{1} & \mathrm{I}_{2}=\mathrm{b}_{2} \mathrm{Y}_{2} \\
\mathrm{~V}_{1}=\mathrm{m}_{1} \mathrm{Y}_{1} & \mathrm{~V}_{2}=\mathrm{m}_{2} \mathrm{Y}_{2} \\
\mathrm{M}_{1}=\mathrm{z}_{1} \mathrm{Y}_{1} & \mathrm{M}_{2}=\mathrm{z}_{2} \mathrm{Y}_{2} \\
& \\
\mathrm{Y}_{1}=\mathrm{C}_{\mathrm{P} 1}+\mathrm{I}_{1}+\mathrm{E}_{\mathrm{o} 1}+\left(\mathrm{V}_{2}-\mathrm{V}_{1}\right)-\mathrm{M}_{1}+\mathrm{C}_{\mathrm{g} 1} \\
\mathrm{Y}_{2}=\mathrm{C}_{\mathrm{P} 2}+\mathrm{I}_{2}+\mathrm{E}_{\mathrm{o} 2}+\left(\mathrm{V}_{1}-\mathrm{V}_{2}\right)-\mathrm{M}_{2}+\mathrm{C}_{\mathrm{g} 2}
\end{array}
$$

donde:

$\mathrm{Y}=$ producto nacional bruto

$\mathrm{C}_{\mathrm{p}}=$ consumo privado

$\mathrm{C}_{\mathrm{g}}=$ consumo público (exógeno)

$\mathrm{I}=$ inversión interna bruta

$\mathrm{M}=$ importaciones extrasubregionales

$\mathrm{V}=$ importaciones intrasubregionales

$\mathrm{E}_{\mathrm{o}}=$ exportaciones extrasubregionales (exógeno)

Las ecuaciones anteriores pueden representarse, en forma de matriz, de la siguiente manera :

$$
\left[\begin{array}{l}
Y_{1} \\
Y_{2}
\end{array}\right]\left[\begin{array}{cc}
s_{1}-b_{1}+z_{1}+m_{1} & -m_{2} \\
-m_{1} & s_{2}-b_{2}+z_{2}+m_{2}
\end{array}\right]=\left[\begin{array}{c}
C_{g 1}+E_{o 1} \\
C_{g 2}+E_{02}
\end{array}\right]
$$

de donde se puede resolver por el vector de ingreso lo siguiente:

$$
\left[\begin{array}{l}
Y_{1} \\
Y_{2}
\end{array}\right]=\left[\begin{array}{cc}
s_{1}-b_{1}+z_{1}+m_{1} & -m_{2} \\
-m_{1} & s_{2}-b_{2}+z_{2}+m_{2}
\end{array}\right]^{-1}\left[\begin{array}{c}
C_{g 1}+E_{o 1} \\
C_{g 2}+E_{o 2}
\end{array}\right]
$$

Para los cinco países centroamericanos, los parámetros del modelo se calcularon utilizando valores promedios de 1990-1992. Se obtuvo la siguiente matriz de multiplicadores:

$\left[\begin{array}{c}Y_{G} \\ Y_{E S} \\ Y_{H} \\ Y_{N} \\ Y_{C R}\end{array}\right]=\left[\begin{array}{lllll}4.19235 & 0.49716 & 0.31855 & 0.48916 & 0.10548 \\ 0.21391 & 4.08816 & 0.12822 & 0.16093 & 0.06074 \\ 0.01681 & 0.03901 & 3.61925 & 0.02242 & 0.00218 \\ 0.01711 & 0.03289 & 0.03796 & 2.40346 & 0.01061 \\ 0.04455 & 0.05203 & 0.04302 & 0.17542 & 1.62662\end{array}\right]\left[\begin{array}{l}C_{g G}+E_{O G} \\ C_{g E S}+E_{O E S} \\ C_{g H}+E_{O H} \\ C_{g N}+E_{O N} \\ C_{g C R}+E_{O C R}\end{array}\right]$

La matriz de multiplicadores indica que si, por ejemplo, las exportaciones extrasubregionales de El Salvador aumentaran 100 dólares, el PIB de este país crecería 409 dólares, mientras que los de Guatemala, Honduras, Nicaragua y Costa Rica subirían 50, 4, 3, y 5 dólares, respectivamente.

Los efectos multiplicadores recibidos por Guatemala y El Salvador son mayores que los recibidos por los otros países. Esto coincide con los resultados de algunos estudios que concluyen que es en esos dos países donde se han concentrado los beneficios de la integración (Cline, 1978).

El cuadro 3 muestra el impacto multiplicador en cada país originado por el aumento simultáneo de 1 dólar en los gastos exógenos (consumo público o exportación al resto del mundo) de los otros países. Se muestra, asimismo, el impacto multiplicador en los otros países de un aumento de 1 dólar en los gastos exógenos del país respectivo. 
CUADRO 3

Centroamérica: Efectos multiplicadores entre las economias de la subregión

\begin{tabular}{lcc}
\hline & $\begin{array}{c}\text { Impacto multiplicador } \\
\text { del resto de } \\
\text { Centroamérica } \\
\text { en cada país }\end{array}$ & $\begin{array}{c}\text { Impacto multiplicador } \\
\text { de cada país } \\
\text { en el resto de } \\
\text { Centroamérica }\end{array}$ \\
\hline Guatemala & 1.4102 & 0.2818 \\
El Salvador & 0.5612 & 0.6210 \\
Honduras & 0.0794 & 0.5710 \\
Nicaragua & 0.0990 & 0.8470 \\
Costa Rica & 0.3140 & 0.1788 \\
\hline
\end{tabular}

Se puede apreciar que Guatemala recibe del resto de la región el impacto multiplicador más grande (1.4102); le siguen El Salvador (0.5612) y Costa Rica (0.3140). Esta es la misma situación que prevaleció en los años sesenta y setenta (Cáceres, 1981). Por otra parte, el mayor efecto multiplicador sobre el resto de Centroamérica lo causa Nicaragua $(0.8470)$, y luego El Salvador y Honduras. Costa Rica origina el menor impacto multiplicador.

Llama la atención que la magnitud de los multiplicadores se ve atenuada por la distancia. En particular, los efectos multiplicadores originados y recibidos por Costa Rica, que se encuentra en el extremo geográfico de la subregión, son los más bajos de todos. Esto refleja la importancia que tiene el costo del transporte en los beneficios de la integración (gráficos 1, 2 y 3 ).

$L o$ anterior indica que los beneficios de la integración —en términos de diseminación del crecimiento económico- estarían determinados en parte por la fricción

GRÁFICO 1

Centroamérica: Efectos multiplicadores recibidos por EI Salvador

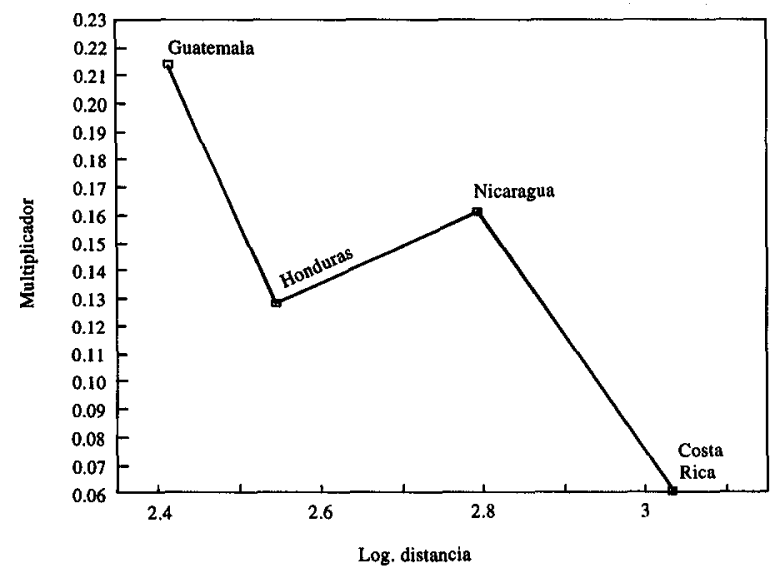

GRÁFICO 2

Centroamérica: Efectos multiplicadores recibidos por Honduras

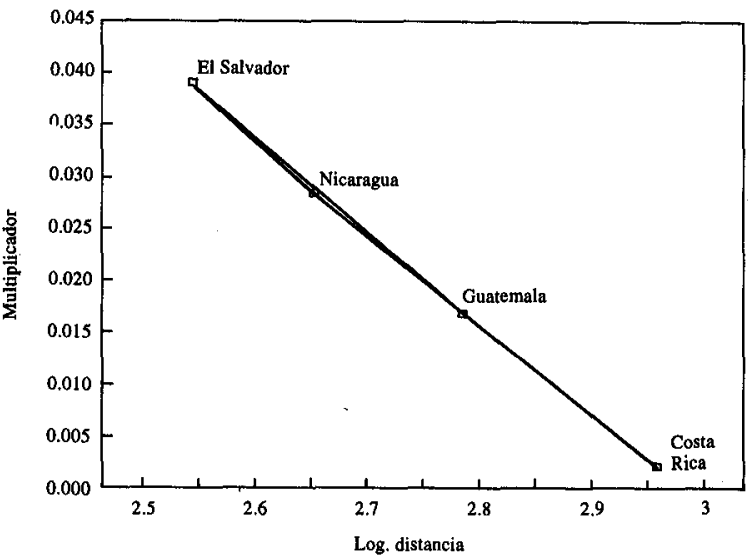

GRÁPICO 3

Centroamérica: Efectos multiplicadores recibidos por Costa Rica

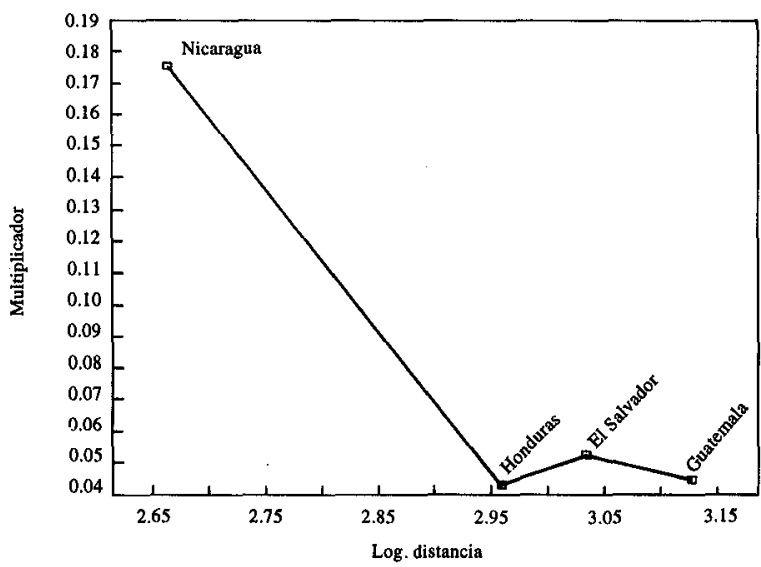

que impone la distancia. De allí el papel estratégico de la red vial y del costo de transporte en la subregión.

\section{Estabilización del crecimiento económico}

El efecto de estabilización derivado de la diseminación del crecimiento entre los países depende de que las economías nacionales no tengan variaciones temporales sincrónicas. Una de las principales determinantes del crecimiento económico de los países centroamericanos es la evolución de los términos de intercambio. Sin embargo, como la correlación entre los términos de intercambio de los países es positiva (cuadro 4), no existiría un efecto estabilizador proveniente del comercio intracentroamericano, aunque las corrientes comerciales se intensificaran. 
CUADRO 4

Centroamérica: Coeficientes de correlación entre los términos de intercambio, 1981-1992

\begin{tabular}{lccccc}
\hline & Guatemala & El Salvador & Honduras & Nicaragua & Costa Rica \\
\hline Guatemala & & & & & 0.74 \\
El Salvador & 1 & 0.69 & 0.52 & 0.37 & 0.81 \\
Honduras & & 1 & 0.05 & 0.30 & 0.05 \\
Nicaragua & & 1 & 1 & 0.59 \\
Costa Rica & & & & 1 \\
\hline
\end{tabular}

Fuente: Cálculos basados en datos de Fondo Monetario Internacional (FMI), Estadísticas financieras internacionales. FMI, Washington D.C., varios números.

GRÁFICO 4

Guatemala: Tasas de crecimiento de sus exportaciones dentro de la subregión y fuera de ella

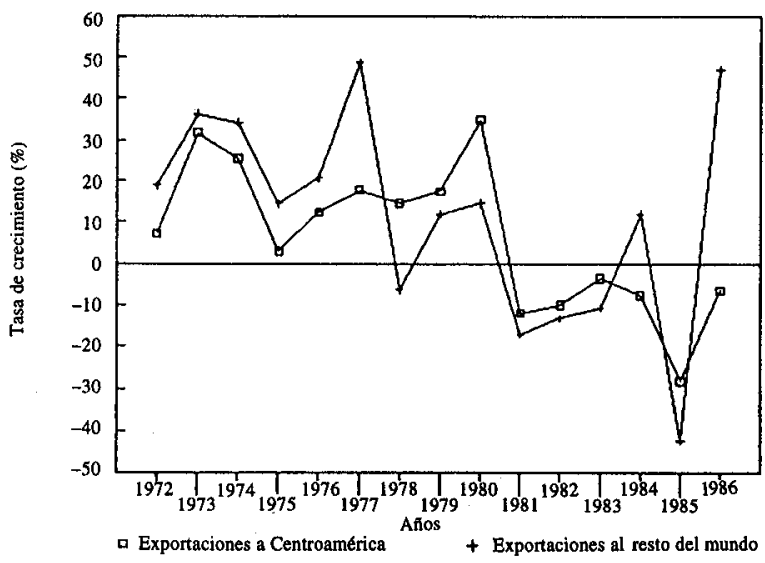

Dada la sincronía en la evolución de las variables exógenas que afectan las economías de los países centroamericanos, no debe extrañar que la variación del comercio extrasubregional e intrasubregional muestre una correlación estrecha (gráficos 4 y 5).

\section{Comercio intraindustrial}

Uno de los beneficios potenciales de la integración es el impulso que puede dar a la industrialización, sustentado en el comercio intraindustrial. Varios estudios han señalado que la similitud en las preferencias de los consumidores de países con igual nivel de desarrollo permite que cada país se especialice en la producción de bienes casi idénticos, diferenciados en aspectos de comercialización, presentación, etc. Este comercio de doble vía de bienes similares facilita la industrialización, ya que un país puede dedicarse a la producción eficiente de un producto, cualquiera sea su ventaja comparativa relativa. en virtud de las eco-
GRÁFICO 5

Nicaragua: Tasas de crecimiento de sus exportaciones dentro de la subregión y fuera de ella

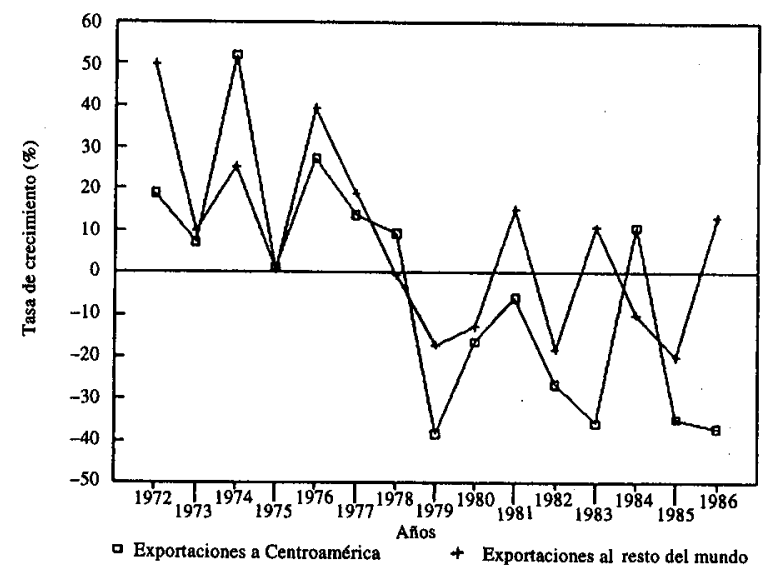

nomías de escala sustentadas en el mercado ampliado que le ofrece la integración ${ }^{2}$. Para calcular el grado en que el comercio intraindustrial prevalece en el comercio exterior, es preciso efectuar un desglose uniforme de las exportaciones e importaciones por categoría de productos. Se le mide por el índice de Grubel-Lloyd (1975), definido como

$$
B=\frac{\sum\left(X_{i}+M_{i}\right)-\sum\left|X_{i}-M_{i}\right|}{\sum\left(X_{i}+M_{i}\right)}
$$

donde $\mathrm{X}_{\mathrm{i}}$ y $\mathrm{M}_{\mathrm{i}}$ representan respectivamente las exportaciones e importaciones del producto $i$. Sobre la base de los datos de 1987 del cuadro 5 se estimaron los valores B para el comercio intraindustrial (cuadro 6).

Se puede apreciar que existe una relación directa

2 Véase en Greenway y Milner (1990) una reseña de lo que se ha escrito sobre el comercio intraindustrial. 
Comercio centroaméricano, 1987

\begin{tabular}{|c|c|c|c|c|c|c|c|c|c|c|c|c|}
\hline & \multicolumn{6}{|c|}{ Comercio intracentroamericano } & \multicolumn{6}{|c|}{ Comercio extracentroamericano } \\
\hline & $\begin{array}{l}\text { División } \\
\text { ClIU }^{a}\end{array}$ & $\begin{array}{l}\text { Export. } \\
\text { Xi }\end{array}$ & $\begin{array}{l}\text { Import. } \\
\mathrm{Mi}\end{array}$ & & Diferen. suma & $\frac{(\mathrm{Xi}-\mathrm{Mi})}{(\mathrm{Xi}+\mathrm{Mi})}$ & $\begin{array}{l}\text { División } \\
\text { CIIU }^{a}\end{array}$ & $\begin{array}{c}\text { Export. } \\
\text { Xi }\end{array}$ & $\begin{array}{l}\text { Import. } \\
\mathrm{Mi}\end{array}$ & $\begin{array}{l}\text { Difere } \\
\text { Xi-Mi }\end{array}$ & $\begin{array}{l}\text { nit suma } \\
\mathrm{Xi}+\mathrm{Mi}\end{array}$ & $\frac{(\mathrm{Xi}-\mathrm{Mi})}{(\mathrm{Xi}+\mathrm{Mi})}$ \\
\hline \multicolumn{13}{|l|}{ EL SALVADOR } \\
\hline Alimentos, bebidas y tabaco & 31 & 9.80 & 27.80 & -18.00 & 37.60 & 0.48 & 31 & 43.80 & 66.40 & -22.60 & 110.20 & 0.21 \\
\hline Textiles, cuero y calzado & 32 & 24.60 & 13.80 & 10.80 & 38.40 & 0.28 & 32 & 36.10 & 30.10 & 6.00 & 66.20 & 0.09 \\
\hline Madera y muebles & 33 & 0.40 & 9.10 & -8.70 & 9.50 & 0.92 & 33 & 0.80 & 1.70 & -0.90 & 2.50 & 0.36 \\
\hline Papel, imprentas y editoriales & 34 & 19.90 & 6.30 & 13.60 & 26.20 & 0.52 & 34 & 2.20 & 41.40 & -39.20 & 43.60 & 0.90 \\
\hline Productos químicos derivados & & & & & & & & & & & & \\
\hline del petróleo, de caucho y plástico & 35 & 35.90 & 60.90 & -25.00 & 96.80 & 0.26 & 35 & 16.50 & 288.60 & -272.10 & 305.10 & 0.89 \\
\hline Productos minerales no metálicos & 36 & 0.60 & 9.50 & -8.90 & 10.10 & 0.88 & 36 & 0.10 & 10.40 & -10.30 & 10.50 & 0.98 \\
\hline Industrias metálicas básicas & 37 & 13.40 & 18.10 & -4.70 & 31.50 & 0.15 & 37 & 1.20 & 54.50 & -53.30 & 55.70 & 0.96 \\
\hline $\begin{array}{l}\text { Productos metálicos, } \\
\text { maquinaria y equipo }\end{array}$ & 38 & 12.10 & 13.60 & -1.50 & 25.70 & 0.06 & 38 & 2.20 & 273.10 & -270.90 & 275.30 & 0.98 \\
\hline Otras manufacturas & 39 & 2.30 & 1.40 & $\begin{array}{r}0.90 \\
92.10\end{array}$ & $\begin{array}{r}3.70 \\
279.50\end{array}$ & $\begin{array}{l}0.24 \\
0.67\end{array}$ & 39 & 0.60 & 4.50 & $\begin{array}{r}-3.90 \\
679.20\end{array}$ & $\begin{array}{r}5.10 \\
874.20\end{array}$ & $\begin{array}{l}0.76 \\
0.22\end{array}$ \\
\hline GUATEMALA & & & & & & & & & & & & \\
\hline Alimentos, bebidas y tabaco & 31 & 40.60 & 22.30 & 18.30 & 62.90 & 0.29 & 31 & 127.30 & 97,90 & 29.40 & 225.20 & 0.13 \\
\hline Textiles, cuero y calzado & 32 & 28.40 & 22.20 & 6.20 & 50.60 & 0.12 & 32 & 14.80 & 54.50 & -39.70 & 69.30 & 0.57 \\
\hline Madera y muebles & 33 & 5.10 & 2.50 & 2.60 & 7.60 & 0.34 & 33 & 5.00 & 3.60 & 1.40 & 8.60 & 0.16 \\
\hline Papel imprentas y editoriales & 34 & 6.70 & 14.00 & -7.30 & 20.70 & 0.35 & 34 & 0.40 & 56.80 & -56.40 & 57.20 & 0.99 \\
\hline $\begin{array}{l}\text { Productos químicos derivados del } \\
\text { petróleo, de caucho y plástico }\end{array}$ & 35 & 85.60 & 42.70 & 42.90 & 128.30 & 0.33 & 35 & 45.10 & 543.20 & -498.10 & 588.30 & 0.85 \\
\hline Productos minerales no metálicos & 36 & 10.20 & 1.30 & 8.90 & 11.50 & 0.77 & 36 & 4.80 & 19.50 & -14.70 & 24.30 & 0.60 \\
\hline Industrias metálicas básicas & 37 & 12.00 & 14.60 & -2.60 & 26.60 & 0.10 & 37 & 1.80 & 79.60 & -77.80 & 81.40 & 0.96 \\
\hline $\begin{array}{l}\text { Productos metálicos, } \\
\text { maquinaria y equipo }\end{array}$ & 38 & 10.50 & 12.90 & -2.40 & 23.40 & 0.10 & 38 & 2.00 & 409.20 & -407.20 & 411.20 & 0.99 \\
\hline Otras manufacturas & 39 & 2.10 & 1.50 & $\begin{array}{r}0.60 \\
91.80\end{array}$ & $\begin{array}{r}3.60 \\
335.20\end{array}$ & $\begin{array}{l}0.17 \\
0.73\end{array}$ & 39 & 0.40 & 13.10 & $\begin{array}{r}-12.70 \\
1137.40\end{array}$ & $\begin{array}{r}411.20 \\
13.50 \\
1479.00\end{array}$ & $\begin{array}{l}0.94 \\
0.23\end{array}$ \\
\hline COSTA RICA & & & & & & & & & & & & \\
\hline Alimentos, bebidas y tabaco & 31 & 14.40 & 17.30 & -2.90 & 31.70 & 0.09 & 31 & 133.00 & 48.10 & 84.90 & 181.10 & 0.47 \\
\hline Textiles, cuero y calzado & 32 & 11.60 & 27.40 & -15.80 & 39.00 & 0.41 & 32 & 63.20 & 58.50 & 4.70 & 121.70 & 0.04 \\
\hline Muebles y maderas & 33 & 2.40 & 0.80 & 1.60 & 3.20 & 0.50 & 33 & 11.10 & 1.80 & 9.30 & 12.90 & 0.72 \\
\hline Papel, imprentas y editoriales & 34 & 4.30 & 8.30 & -4.00 & 12.60 & 0.32 & 34 & 6.20 & 94.60 & -88.40 & 100.80 & 0.88 \\
\hline Productos químicos derivados del & 35 & 36.60 & 36.90 & -0.30 & 73.50 & . & 35 & 6400 & 44020 & -37620 & 504.20 & 075 \\
\hline Productos minerales no metálicos & 36 & 6.40 & 2.60 & 3.80 & 9.00 & 0.42 & 36 & 6.80 & 19.30 & -12.50 & 26.10 & 0.48 \\
\hline Industrias metálicas básicas & 37 & 13.40 & 6.00 & 7.40 & 19.40 & 0.38 & 37 & 5.90 & 93.20 & $-87,30$ & 99.10 & 0.88 \\
\hline $\begin{array}{l}\text { Productos metálicos, } \\
\text { maquinaria y equipo }\end{array}$ & 38 & 14.20 & 6.00 & 8.20 & 20.20 & 0.41 & 38 & 25.40 & 421.60 & -396.20 & 447.00 & 089 \\
\hline Otras manufacturas & 39 & 3.70 & 2.20 & 1.50 & 5.90 & 0.25 & 39 & 21.70 & $\begin{array}{r}30.30 \\
30.30\end{array}$ & -8.60 & 52.00 & 0.17 \\
\hline & & & & 45.50 & 214.50 & 0.79 & & & & 1068.10 & 1544.90 & 0.31 \\
\hline NICARAGUA & & & & & & & & & & & & \\
\hline Alimentos, bebidas y tabaco & 31 & 1.50 & 3.00 & -1.50 & 4.50 & 0.33 & 31 & 52.50 & 36.40 & 16.10 & 88.90 & 0.18 \\
\hline Textiles, cuero y calzado & 32 & 1.00 & 8.80 & -7.80 & 9.80 & 0.80 & 32 & 1.90 & 49.30 & -47.40 & 51.20 & 0.93 \\
\hline Madera y muebles & 33 & 0.70 & 0.10 & 0.60 & 0.80 & 0.75 & 33 & 1.30 & 6.50 & $-5,20$ & 7.80 & 0.67 \\
\hline Papel, imprentas y editoriales & 34 & 1.10 & 1.20 & -0.10 & 2.30 & 0.04 & 34 & 0.10 & 21.50 & -21.40 & 21.60 & 0.99 \\
\hline Productos químicos, derivados del & 35 & 450 & 1900 & -1450 & 2350 & 0.62 & 35 & 140 & 33880 & -33740 & 340.20 & 0.99 \\
\hline Productos minerales no metálicos & 36 & 0.30 & 0.50 & -0.20 & $\begin{array}{r}0.80 \\
0.80\end{array}$ & 0.25 & 36 & & $\begin{array}{r}30.00 \\
9.60\end{array}$ & -9.60 & 9.60 & 1.00 \\
\hline Industrias metálicas básicas & 37 & 3.40 & 1.80 & 1.60 & 5.20 & 0.31 & 37 & 1.10 & 40.70 & -39.60 & 41.80 & 0.95 \\
\hline Productos metálicos, & & & & & & & & & & & & \\
\hline maquinaria y equipo & 38 & 2.00 & 5.70 & -3.70 & 7.70 & 0.48 & 38 & 0.50 & 248.60 & -248.10 & 249.10 & 1.00 \\
\hline Otras manufacturas & 39 & 0.10 & 0.60 & -0.50 & 0.70 & 0.71 & 39 & 3.60 & 7.40 & -3.80 & 11.00 & 0.35 \\
\hline & & & & 30.50 & 55.30 & 0.45 & & & & 728.60 & 821.20 & 0.11 \\
\hline HONDURAS & & & & & & & & & & & & \\
\hline Alimentos, bebidas y tabaco & 31 & 4.00 & 6.40 & -2.40 & 10.40 & 0.23 & 31 & 110.20 & 63.40 & 46.80 & 173.60 & 0.27 \\
\hline Textiles, cuero y calzado & 32 & 3.70 & 2.20 & 1.50 & 5.90 & 0.25 & 32 & 1.90 & 29.50 & -27.60 & 31.40 & 0.88 \\
\hline Madera y muebles & 33 & 3.80 & - & 3.80 & 3.80 & 1.00 & 33 & 40.20 & 0.80 & 39.40 & 41.00 & 0.96 \\
\hline Papel, imprentas y editoriales & 34 & 0.40 & 4.80 & -4.40 & 5.20 & 0.85 & 34 & 2.60 & 38.50 & -35.90 & 41.10 & 0.87 \\
\hline Productos químicos, derivados & & & & & & & & & & & & \\
\hline del petróleo, de caucho y plástico & 35 & 4.60 & 3.50 & 1.10 & 8.10 & 0.14 & 35 & 4.20 & 329.20 & -325.00 & 333.40 & 0.97 \\
\hline Productos minerales no metálicos & 36 & 0.30 & 4.60 & -4.30 & 4.90 & 0.88 & 36 & 2.60 & 14.20 & -11.60 & 16.80 & 0.69 \\
\hline Industrias metálicas básicas & 37 & 1.50 & 6.30 & 4.80 & 7.80 & 0.62 & 37 & 0.20 & 40.90 & 40.70 & 41.10 & 0.99 \\
\hline Productos metálicos, & & & & & & & & & & & & \\
\hline maquinaria y equipo & 38 & 1.40 & 1.30 & 0.10 & 2.70 & 0.04 & 38 & 0.10 & 247.90 & -247.80 & 248.00 & 1.00 \\
\hline Otras manufacturas & 39 & 0.50 & 0.20 & 0.30 & 0.70 & 0.43 & 39 & 0.80 & 18.90 & -18.10 & 19.70 & 0.42 \\
\hline & & & & 22.70 & 49.50 & 0.46 & & & & 792.90 & 946.10 & 0.16 \\
\hline
\end{tabular}

Fuente: Datos tomados de Bulmer-Thomas (1992a).

a Los títulos de las divisiones de la Clasificación Industrial Internacional Uniforme (CIIU) están abreviados. 
CUADRO 6

Centroamérica: Indices de Grubel-Lloyd de comercio intraindustrial

\begin{tabular}{lcc}
\hline & $\begin{array}{c}\text { Comercio } \\
\text { intracentroamericano }\end{array}$ & $\begin{array}{c}\text { Comercio } \\
\text { extracentroamericano }\end{array}$ \\
\hline Guatemala & 0.73 & 0.23 \\
El Salvador & 0.67 & 0.22 \\
Honduras & 0.46 & 0.16 \\
Nicaragua & 0.45 & 0.11 \\
Costa Rica & 0.79 & 0.31 \\
\hline
\end{tabular}

entre el nivel de desarrollo, representado por el ingreso per cápita, y el índice de Grubel-Lloyd, tanto en el comercio dentro de la subregión como en el extracentroamericano. Los valores más altos corresponden a Costa Rica, seguidos de los correspondientes a Guatemala, El Salvador, Honduras y Nicaragua. En efecto, en Costa Rica el $79 \%$ del comercio subregional es de carácter intraindustrial; este porcentaje es similar a los correspondientes al comercio entre los países desarrollados. Lo anterior indica que la integración permite a los países centroamericanos producir y exportar bienes que a falta de ella probablemente no figurarían en su comercio exterior.

Asimismo, Costa Rica muestra el valor más alto - de 0.31- en el comercio extracentroamericano, seguido de Guatemala (0.23), El Salvador (0.22), Honduras (0.16) y Nicaragua (0.11). Es del caso señalar que, para la subregión en su conjunto, en 1974 los índices de comercio intraindustrial dentro de Centroamérica y fuera de ella fueron de 0.505 y 0.025 (Laird. 1981).

A nivel de ramas industriales, se calcularon además los indicadores de comercio intraindustrial propuestos por Balassa (1966) y definidos como:

$$
\frac{\left|X_{i}-M_{i}\right|}{X_{i}+M_{i}}
$$

Este índice va de cero, cuando todo el comercio es intraindustrial, $\left(X_{i}=M_{i}\right)$, a uno cuando no existe en doble vía. El cuadro 5 muestra que en el intercambio centroamericano el comercio intraindustrial es importante en todos los países en los rubros industrias metálicas básicas, productos metálicos, maquinaria y equipo y otras manufacturas. También es importante en textiles y productos químicos. Esto podría indicar la ausencia de especialización a nivel de país, lo que significaría que todos los países tendrían las mismas "ventajas comparativas".

En el intercambio extracentroamericano básica- mente con los Estados Unidos, Japón y Alemania, los índices de comercio intraindustrial para Honduras y Nicaragua son poco significativos en todos los rubros, excepto en el de alimentos, bebidas y tabaco. Este rubro muestra índices más elevados en todos los países, lo cual es congruente con los postulados de las "ventajas comparativas".

Los resultados anteriores coinciden con los de estudios de varios autores en señalar que el comercio intraindustrial es más significativo entre países con similares niveles de ingreso (Gray, 1988). Específicamente, Balassa y Bauwens (1987) encontraron que las corrientes comerciales intracentroamericanas en el marco de la Asociación Latinoamericana de Libre Comercio (ALALC) eran primordialmente del tipo intraindustrial, y Greenway (1987) obtuvo un resultado similar para la CEE.

De allí que la prevalencia del comercio intraindustrial en la integración centroamericana le ofrezca facilidades para su industrialización, ya que productos similares y diferenciados encuentran un mercado ampliado que favorece series de producción mayores, con las consiguientes economías de escala (Balassa, 1979). ${ }^{3}$

\section{Ampliación del mercado}

Los beneficios de la integración económica han sido analizados tradicionalmente en un marco de competencia perfecta, situación que no siempre se da en los países en desarrollo, donde predomina una alta concentración de empresas industriales (N. Lee, 1984 y 1992). Tal es el caso en Centroamérica (Rapoport, 1978). De allí que en estos países el modelo de competencia imperfecta tal vez sea más útil para ilustrar los beneficios de la integración. Este modelo supone que en el mercado interno rige una estructura de competencia monopolística. Por lo tanto, el precio está determinado por los costos medios de las empresas que integran la industria, y no por sus costos marginales. A medida que aumenta el número de empresas en la industria se incrementa el costo promedio, ya que el mercado de cada firma se reduce (Helpman y Krugman, 1986).

\footnotetext{
3 Bulmer-Thomas (1992a) ha apuntado que el renglón alimentos, bebidas y tabaco, que origina el $50 \%$ de la producción manufacturera de la región, representa sólo $15 \%$ de las exportaciones intrasubregionales. Este autor señala que la expansión del comercio en este rubro, mediante la eliminación de las limitaciones no arancelarias existentes, impulsaría significativamente el comercio intracentroamericano, especialmente el de Honduras y Nicaragua. Los índices apuntan a la conveniencia de expandir el comercio de esos productos para aprovechar las economías de escala inherentes al comercio intraindustrial.
} 
En el gráfico 6, partiendo del caso de un país (Honduras, por ejemplo), tenemos que $\mathrm{CC}$ representa la relación directa entre el número de empresas que participan en la industria y sus costos promedios. Además, al aumentar el número de empresas crece la competencia entre las mismas y el precio se reduce. Así, PP indica la relación inversa entre la cantidad de empresas y el precio prevaleciente en la industria. La condición de equilibrio resulta de la intersección de $\mathrm{CC}$ y $\mathrm{PP}$, donde el precio $\left(\mathrm{P}_{\mathrm{o}}\right)$ es igual al costo promedio que no induce la entrada ni la salida de firmas y determina el número de empresas nacionales $\left(\mathrm{N}^{\circ}\right)$. Con la integración, el aumento de la competencia monopolística, debido a la participación de empresas de los demás países, conduce a una reducción del precio. Asimismo, en la determinación del costo promedio de las empresas ahora influyen el mercado ampliado y el mayor número de firmas. La expansión del mercado tiende a disminuir el costo promedio de las empresas mientras que el aumento de éstas tiende a elevarlo. El resultado es un desplazamiento de $\mathrm{CC}$ hacia afuera $\left(\mathrm{C}^{1} \mathrm{C}^{1}\right)$ que implica menores costos promedios y un mayor número de empresas. La solución de equilibrio radica en un número de empresas menor que la totalidad de empresas existentes antes de la integración y un precio menor al precio prevaleciente con anterioridad a la integración, derivado de mayores volúmenes de ventas por empresa y una mayor competencia. El gráfico 6 muestra un nuevo precio de equilibrio $\left(\mathrm{P}^{1}\right)$ y el nuevo número de firmas $\left(\mathrm{N}^{1}\right)$ resultantes de la competencia monopolística a escala subregional.
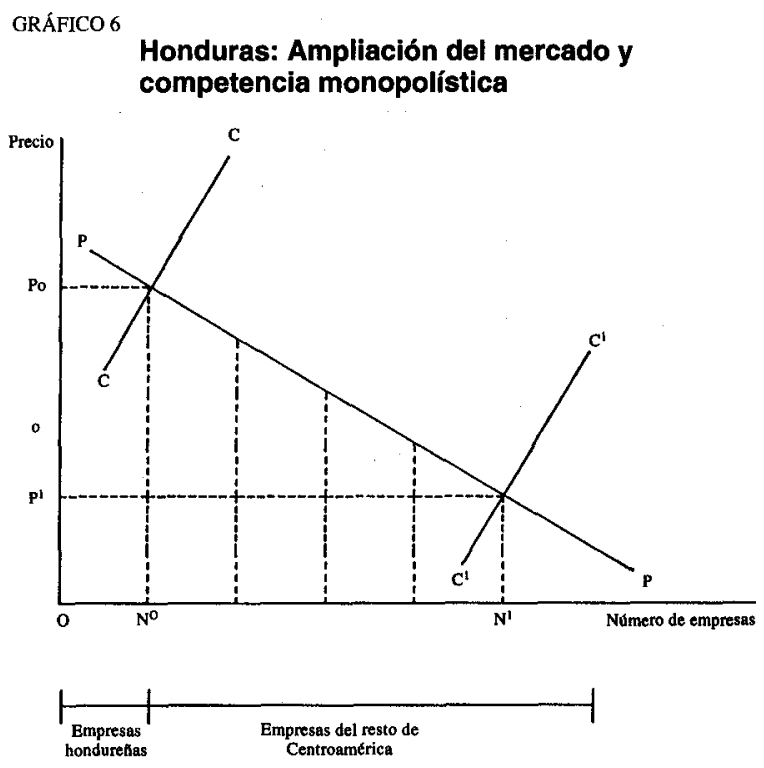

Lo anterior señala que la integración otorga a cada país centroamericano acceso a los mercados de los otros países del área. Esto no ocurre con la apertura unilateral global, la cual no garantiza un mercado a cambio. En ese caso, el precio que regiría en la industria interna sería el precio mundial.

Rodrik (1988 y 1990) ha mostrado que, al obviar el supuesto de competencia perfecta en el mercado nacional, la reforma comercial se manifiesta de tres formas, y cada una de ellas ejerce un impacto positivo cuando su comportamiento es el siguiente: i) expansión de las importaciones de los bienes que hasta entonces estaban protegidos y contracción de los correspondientes sectores internos; ii) aumento de la producción de empresas oligopólicas, y iii) expansión de las empresas que aprovechan economías de escala. Cabe destacar que el primer efecto podría entrar en conflicto con los otros dos, ya que los sectores protegidos generalmente tienen carácter oligopólico y disfrutan de economías de escala. ${ }^{4}$ Es decir, en un análisis más general de las distintas repercusiones de la reforma comercial, se aprecia que la contracción de las industrias protegidas redunda en un incremento de bienestar, pero que éste podría verse anulado si tales industrias tienen estructuras oligopolísticas y si se pierde la eficacia técnica derivada de las economías de escala. Así el resultado neto puede ser ambiguo.

Rodrik (1988) señala que este conflicto podría ser resuelto por la vía de un aumento de las exportaciones de los sectores previamente protegidos. Conviene recalcar que la integración ofrece la oportunidad de incrementar las exportaciones de estos y otros sectores, lo cual garantizaría los beneficios derivados de la apertura comercial unilateral. De allí que la integración y la apertura sean complementarias. Se aprecia también que el supuesto de competencia perfecta puede ser inadecuado para analizar los efectos de la apertura externa y de la integración.

En este contexto cabe señalar que, a través de un

4 Cline (1978) hace una cuantificación de las economías de escala en la industria centroamericana. La marcada concentración industrial que se observa en los países centroamericanos es destacada por Rapoport (1978), quien señala que, a nivel regional, la concentración industrial se reduce con relación al grado de concentración nacional, volviéndose similar a la concentración prevaleciente en los Estados Unidos. En síntesis, dice el autor, estas medidas muestran una concentración industrial extremadamente alta para cada país centroamericano considerado por separado, y una concentración global bastante menor, comparable con la de los Estados Unidos, si se considera la subregión como una sola unidad. Y agrega que el Mercado Común Centroamericano probablemente contribuyó en una medida importante a reducir el poder monopolístico y aligopólico en Centroamérica (p. 670). 
modelo de competencia imperfecta, Smith y Venables (1988) encontraron que la integración de mercados en la CEE se ha traducido en un incremento de sus exportaciones extrarregionales, en virtud de la reducción de los precios debida a las economías de escala posibilitadas por el mercado europeo. Otros estudios han encontrado que a nivel de industrias y empresas la concentración industrial está relacionada inversamente con la expansión de las exportaciones (Glejser,
Jacquemin y Petit, 1980) y que la concentración disminuye con el tamaño del mercado (Meller, 1978).

Asimismo, se ha señalado que las exportaciones extrasubregionales no tradicionales de Costa Rica estuvieron precedidas por la experiencia de exportar los mismos bienes al mercado centroamericano. Estos resultados se interpretaron como prueba de que la integración ofrece la oportunidad de "aprender a exportar exportando" (Webb y Fackler, 1993).

\section{III}

\section{Obstáculos para aprovechar los beneficios de la integración}

La sección anterior muestra que la integración ha acarreado beneficios a los países centroamericanos en términos de crecimiento económico, industrialización facilitada por el comercio intraindustrial y mayor competencia en el mercado ampliado. Se nota, sin embargo, que esos beneficios se focalizan en los países de mayor desarrollo relativo. Al respecto se puede señalar que tales beneficios han estado asociados al grado de participación del país miembro en el comercio dentro de la subregión. Cabe preguntarse entonces cuáles son los factores que determinan el desempeño de las exportaciones intrasubregionales de los países centroamericanos. Se ha argumentado también que el mayor tamaño de las economías de los países de más desarrollo relativo ha facilitado el proceso de industrialización mediante las economías de escala y la mejor infraestructura física (Cáceres, 1981). En otras palabras, que una mayor exportación de bienes primarios sentó las bases para una mayor capacidad industrial cuando se inició el programa de integración en los años sesenta. Pero es de especial interés examinar las variables que han mostrado tener incidencia en las exportaciones dentro de la subregión.

\section{Costo de transporte}

El alto costo de "transporte y seguro" de las exportaciones de los países centroamericanos ha pasado relativamente inadvertido. Según el Fondo Monetario Internacional (FMI) este costo puede calcularse como la diferencia entre las exportaciones de un país hacia otra región o país, y sus importaciones desde la re- gión o el país en cuestión. En los costos de transporte así estimados para el comercio con países en desarrollo, que en este caso comprende básicamente el comercio intracentroamericano, se puede apreciar que este rubro es particularmente elevado para Honduras y Nicaragua (cuadro 7).

\begin{tabular}{ll} 
CUADRO 7 & $\begin{array}{l}\text { Centroamérica: Estimación del costo de } \\
\text { transporte y seguro, 1992 } \\
\text { (Porcentajes de las exportaciones) }\end{array}$ \\
\hline Guatemala & \\
El Salvador & 6.2 \\
Honduras & 0.8 \\
Nicaragua & 52.8 \\
Costa Rica & 14.1 \\
\end{tabular}

Fuente: Calculado sobre la base de cifras del Fondo Monetario Internacional (FMI), Direction of Trade Statistics Yearbook 1993b, Washington, D. C., 1993.

\section{Bajos niveles de capital humano}

Entre los factores de producción que afectan la capacidad de exportación de un país, la cuantía del capital humano ocupa un lugar especial. El papel determinante de este capital en la creación de ventajas competitivas ha sido cuantificado para los países de la CEE, por Neven y Roller (1991). Además, Balassa y Bauwens (1988), en un estudio de los factores determinantes del comercio bilateral para una muestra de 18 países desarrollados y 20 en desarrollo, concluye- 
ron que las exportaciones entre pares de países dependían, entre otras variables, de la razón entre el capital humano del país exportador y el del país importador. De acuerdo con estos autores, si esta razón aumentara $1 \%$, las exportaciones crecerían entre $0.123 \%$ y $0.233 \%$, según se trate de comercio entre países en desarrollo o desarrollados.
En las investigaciones señaladas se ha usado como indicador de capital humano la tasa de matrícula en la escuela secundaria más cinco veces la tasa de matrícula en el nivel terciario. Este índice se calculó para los países centroamericanos en 1990 (cuadro 8).

La importancia de la cuantía del capital humano como determinante de las corrientes comerciales in-

CUADRO 8

Centroamérica: Indicadores de capital humano, 1990

\begin{tabular}{|c|c|c|c|c|}
\hline & \multicolumn{2}{|c|}{ Tasa de matrícula } & \multirow[t]{2}{*}{ Indice } & \multirow{2}{*}{$\begin{array}{l}\text { Exportaciones al resto de } \\
\text { Centroamérica, } 1992 \\
\text { (millones de dólares) }\end{array}$} \\
\hline & $\begin{array}{c}\text { Nivel } \\
\text { secundario }\end{array}$ & $\begin{array}{c}\text { Nivel } \\
\text { terciario }\end{array}$ & & \\
\hline Honduras & 32 & 9 & 77 & 34.3 \\
\hline Guatemala & 21 & $\ldots$ & $\ldots$ & 353.0 \\
\hline El Salvador & 29 & 17 & 114 & 207.1 \\
\hline Nicaragua & 43 & 8 & 83 & 51.9 \\
\hline Costa Rica & 41 & 24 & 161 & 224.5 \\
\hline
\end{tabular}

Fuente: Cálculos sobre la base de datos del Banco Mundial, Informe del desarrollo mundial 1991, Washington D.C., 1991.

tracentroamericanas puede apreciarse al estimar una ecuación que expresa las exportaciones del país i al país $\mathbf{j}\left(\mathrm{E}_{\mathrm{ij}}\right)$, en función de los índices de capital humano del país exportador $\left(\mathrm{H}_{i}\right)$ e importador $\left(\mathrm{H}_{j}\right)$ y la distancia en kilómetros entre ambos países $\left(\mathrm{D}_{\mathrm{ij}}\right)$. Los resultados de esa estimación, sobre la base de una muestra del comercio intrarregional de El Salvador, Honduras, Nicaragua y Costa Rica, en 1992, y utilizando los índices de capital humano mostrados en el cuadro 8 , son los siguientes: ${ }^{5}$

$\begin{array}{rlr}\log \left(\mathrm{E}_{\mathrm{ij}}\right)= & -4.8536-0.8027 \log \left(\mathrm{D}_{\mathrm{ij}}\right)+ & 2.9216 \log \left(\mathrm{H}_{\mathrm{i}}\right) \\ & (0.90) \quad(1.48) & (3.45) \\ & & \\ -0.1408 \log \left(\mathrm{H}_{\mathrm{j}}\right) & \mathrm{R}^{2}=0.54 \\ (0.19) & \mathrm{DW}=1.62\end{array}$

Puede apreciarse así que el factor determinante del comercio intracentroamericano es el nivel de capital humano del país exportador.

Un resultado similar se detectó al usar datos de

5 Los datos sobre el comercio intracentroamericano están tomados de CEPAL, 1993.
1965 para los cinco países centroamericanos e incorporar las variables PIB del país exportador $\left(\mathrm{Y}_{\mathrm{i}}\right)$ y del importador $\left(\mathrm{Y}_{\mathrm{j}}\right)$ :

$$
\begin{aligned}
& \log \left(\mathbf{E}_{\mathrm{ij}}\right)=-7.8331+1.3591 \log \left(\mathrm{Y}_{\mathrm{j}}\right)+0.7179 \log \left(\mathrm{Y}_{\mathrm{j}}\right) \\
& \text { (1.93) (4.01) (2.12) } \\
& -1.1416 \log \left(\mathrm{D}_{\mathrm{ij}}\right)+0.6901 \log \left(\mathrm{H}_{\mathrm{i}}\right) \\
& \text { (4.40) (2.40) } \\
& +0.2749 \log \left(\mathrm{H}_{\mathrm{j}}\right) \quad \mathrm{R}^{2}=0.71 \\
& \text { (0.95) } \quad \mathrm{DW}=1.94
\end{aligned}
$$

El índice de capital humano del país exportador es significativo, pero de magnitud inferior al correspondiente a 1990. Esto indicaría que, a través del tiempo, el papel de los recursos humanos ha ido adquiriendo mayor importancia en el comercio intrasubregional. De allí que los esfuerzos en favor de la integración y de la modernización económica pueden ser fútiles para los países centroamericanos si no se elevan sustancialmente sus niveles de capital humano.

Respecto de la evolución de los índices de capital humano en el período 1960-1990 (cuadro 9) se puede apreciar que Costa Rica exhibe valores más 
elevados que los de los otros países, mientras que los de Guatemala muestran un menor dinamismo. Además, estos indicadores decrecen en la segunda mitad de los años ochenta, excepto en El Salvador, país que mostró en 1990 una mejoría considerable respecto del inicio de los años ochenta.

CUADRO 9

Centroamérica: Indicadores de capital humano

\begin{tabular}{lrrrrrr}
\hline & \multicolumn{3}{c}{ Años } & & \\
& 1960 & 1975 & 1978 & 1983 & 1985 & 1990 \\
\hline Guatemala & 17 & 33 & 40 & 51 & 56 & $\ldots$ \\
El Salvador & 16 & 58 & 63 & 84 & 97 & 114 \\
Honduras & 13 & 43 & 48 & 83 & 81 & 77 \\
Nicaragua & 12 & 51 & 81 & 108 & 93 & 83 \\
Costa Rica & 46 & 128 & 141 & 174 & 171 & 161 \\
\hline
\end{tabular}

Fuente: Cálculos basados en Banco Mundial, Informe sobre el desarrollo mundial, Washington, D.C., varios números.

Dadas las disparidades en los niveles de desarrollo de capital humano, una apropiada política subregional podría ser la de establecer la libre movilidad de la mano de obra. Esta medida podría ser más efectiva en el tiempo que tratar de incrementar aceleradamente los acervos de capital en los países rezagados, aunque esto último es de particular urgencia. En efecto, los beneficios económicos de la movilidad de la mano de obra son considerables, según los análisis realizados por De Franco (1993).

\section{Ausencia de medidas de equidad}

No obstante las diferencias en el aprovechamiento de los beneficios de la integración, no ha existido en el contexto centroamericano una política de equidad o de compensación para los países de menor desarrollo.
Se debe señalar que las disparidades económicas entre los países de la subregión aumentaron durante los años ochenta. El coeficiente de dispersión del ingreso per cápita, es decir, la desviación estándar dividida por el valor promedio, ha mostrado una tendencia hacia una mayor dispersión de los niveles de dicho ingreso (gráfico 7). Esto se podría interpretar como una indicación de que los países centroamericanos se han vuelto más heterogéneos. En el caso de la Unión Europea, el Tratado de Maastricht señala el principio de cohesión, definido como la reducción de las disparidades regionales, como la pauta fundamental de la integración europea ${ }^{6}$ (Begg y Mayes, 1993). En ese sentido habría que diseñar los componentes de equidad en el marco de la integración centroamericana para maximizar los beneficios de la integración.

\section{IV}

\section{Los costos de la integración}

Con relación a los costos de la integración, varios estudios recientes han computado el costo en que incurrirían los países centroamericanos por la "no integración", entendida como tal la suspensión del comercio intrasubregional. En particular, Gallardo (1992) ha estimado que dicho costo podría ser significativo para todos los países, excepto para Honduras. No obstante la validez de estos trabajos, existen otros costos que pueden ser muy significativos y que han recibido relativamente poca atención. Estos se originan en la falta de coordinación de las políticas que inciden en la integración, es decir, allí donde la integración es un hecho, la ausencia de coordinación podría representar costos significativos, los que se analizan a continuación.

\footnotetext{
6 En los países de la Organización de Cooperación y Desarrollo Económicos (OCDE), el índice de dispersión del ingreso per cápita ha disminuido de 0.45 en 1950 a 0.28 en 1985 (Dowrick y Nguyen, 1989).
} 
GRÁFICO 7

Centroamérica: Dispersión en los niveles de Ingreso per cápita

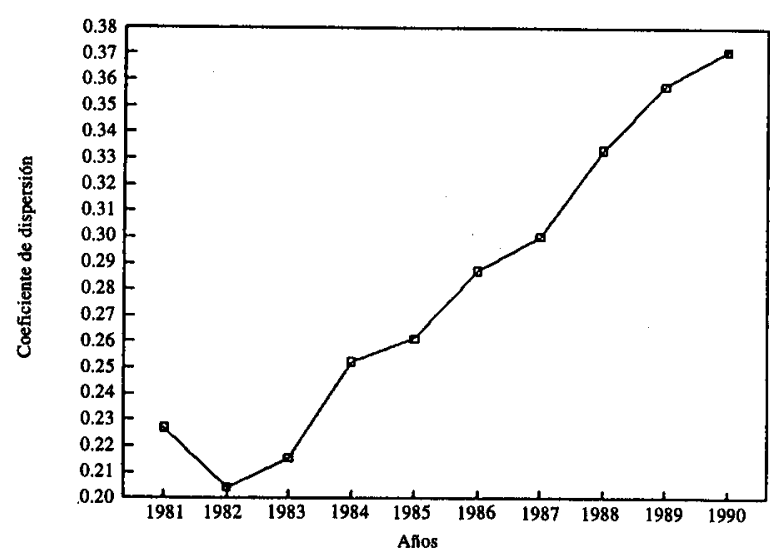

\section{El arbitraje en los mercados de monedas}

Un fenómeno que pone de relieve la necesidad de coordinación es el arbitraje de monedas, es decir, la compraventa de un bien (moneda) que tiene diferentes precios en dos mercados distintos para obtener ganancias. En términos específicos, una persona puede viajar de Guatemala a El Salvador y cambiar sus quetzales por colones a un tipo de cambio $\mathrm{C} / \mathrm{Q}$, para luego comprar dólares a una tasa $\mathrm{C} / \mathrm{D}$. Este individuo puede regresar a Guatemala, cambiar los dólares por quetzales a un tipo de cambio Q/D y obtener ganancias. Se puede demostrar que si el tipo de cambio de mercado del colón al quetzal es mayor que el tipo de cambio cruzado (colón-dólar/quetzal-dólar), hay posibilidades de ganancias. Es decir, si C/Q > C/D/Q/D se cumple la condición para que los quetzales fluyan a El Salvador y así aumenten la demanda de colones y dólares.

El gráfico 8 presenta, para el período 1988-1990, la ganancia $\mathrm{C} / \mathrm{Q}-\mathrm{C} / \mathrm{D} / \mathrm{Q} / \mathrm{D}$ examinada anteriormente en colones por quetzal transado. Se puede notar que en la mayoría de los casos el resultado tiene signos positivos. Esto indica que El Salvador es una fuente de abastecimiento de dólares para Guatemala. Por otro lado, esta entrada persistente de quetzales a El Salvador muestra que, para fines de programación monetaria, Guatemala debería considerar qué parte de su oferta de moneda fluye hacia El Salvador. A la vez, El Salvador debería tomar en cuenta qué porción de la masa monetaria que circula en el país está constituida por quetzales. Así, se aprecia que en estas economías circulan al menos dos monedas. Esto tiene relevancia especial tanto para la precisión de la programación financiera como para el diseño de programas de ajuste y exige un esfuerzo de coordinación de la política cambiaria entre los países centroamericanos.

GRÁFICO 8

Guatemala y El Salvador: Ganancla por arbltraje (Colones por quetzal transado)

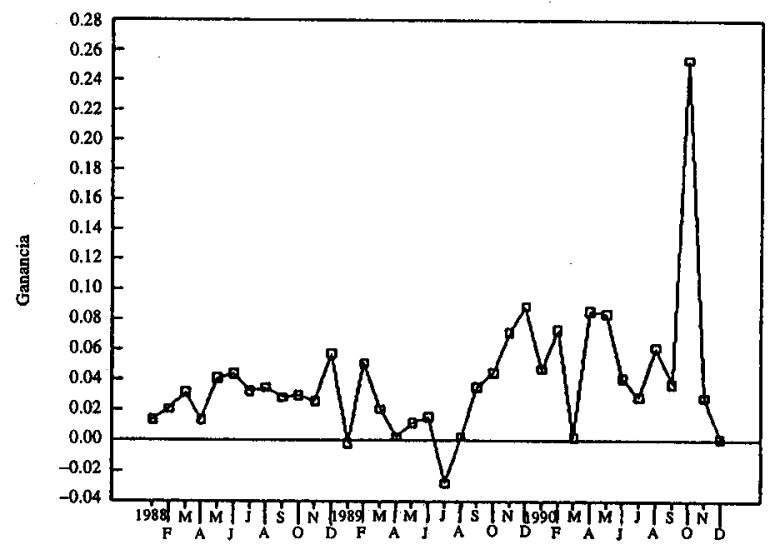

\section{Sustitución de monedas}

En relación con el punto anterior se debe señalar que algunos estudios han encontrado que en El Salvador y Guatemala las demandas de sus respectivas monedas son interdependientes, en el sentido de que la demanda de colones en El Salvador está determinada parcialmente por la oferta de quetzales en Guatemala (Cáceres y Suay, 1988a). Cabe preguntarse entonces cuál debería ser el agregado monetario más efectivo en cada país para los fines de la programación monetaria. Asimismo, se ha encontrado evidencia empírica de que la tasa de inflación de El Salvador está determinada principalmente por una variable compuesta de la agregación de las ofertas monetarias de Guatemala y Costa Rica (Cáceres y Suay, 1988b). La referida interdependencia se ha observado también en los tipos de cambio de estos países. De hecho, por medio de las pruebas de causalidad de Granger se encontró que el tipo de cambio de Guatemala determina el tipo de cambio de $\mathrm{El}$ Salvador (Cáceres y Núñez-Sandoval, 1992). Dado que los tipos de cambio de estos países son determinados por su oferta monetaria, la expansión monetaria de un país tiene repercusiones en el tipo de cambio del otro. De esa manera, la estabilidad cambiaria, que es de especial importancia para el comercio intracentroamericano, dependería en parte de variables externas al 
país en cuestión. Esto apunta a la necesidad de un marco operativo de coordinación de políticas monetarias, cuya ausencia podría representar costos apreciables.

\section{Diferencial cambiario}

Otro fenómeno que confirma la necesidad de coordinación es el diferencial cambiario entre el precio de compra y el precio de venta del dólar en Guatemala y El Salvador, que representa un significativo costo de transacción. Este diferencial es mayor en Guatemala que en El Salvador, lo que obedece a los mayores volúmenes que se transan en el segundo (gráfico 9).

Además, puede verse que los dos diferenciales muestran una trayectoria inversa, lo que confirma que cuando el volumen de operaciones es bajo en un país es alto en el otro y viceversa. El diferencial correspondiente al tipo de cambio del quetzal con respecto al colón (gráfico 10) es mucho más elevado que el de

GRÁFICO 9

El Salvador y Guatemala: Diferencial cambiario en mercados del dólar

(Precio de venta-precio de compra / precio promedio)

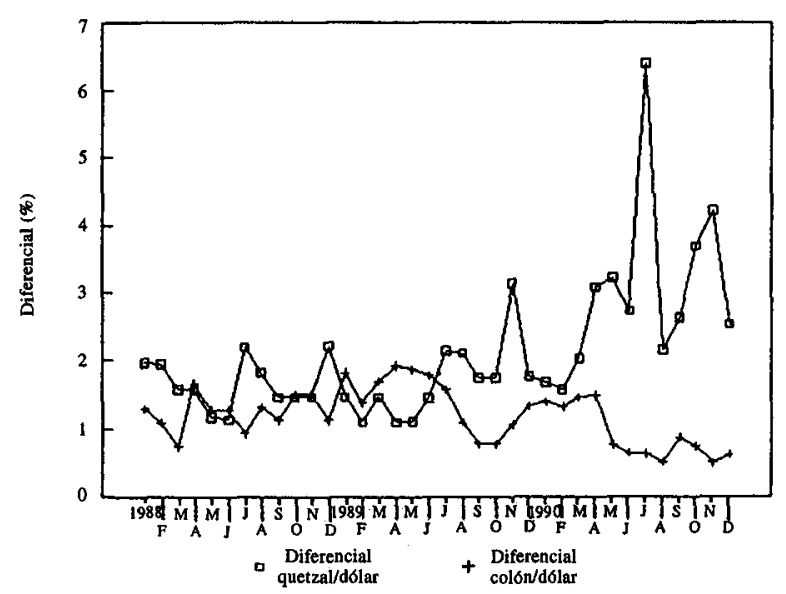

las otras dos monedas, en atención a su menor volumen de transacción.

Los ejemplos anteriores representan la auténtica "integración monetaria" que, de hecho, tiene lugar en el marco de las fuerzas de oferta y demanda de monedas y que a su vez reflejan los comportamientos de las políticas monetarias y fiscales de esos países. También dejan en claro que una integración de esta naturaleza, sin la coordinación debida, puede ser costosa. De ahí la necesidad de establecer los mecanismos para la convergencia y la vigilancia multilateral de tales políticas. ${ }^{7}$ Así, la eliminación de los costos de la integración, de hecho requeriría que los países incurriesen en el "costo" de reducir su autonomía en la conducción de sus políticas monetarias y fiscales. Es decir, los países no podrían establecer sus programas monetarios y fiscales en forma autónoma, sino que tendrían que hacerlo en un ejercicio concertado y sujetos a las necesidades subregionales.

GRÁFICO 10

Diferencial cambiario colón/quetzal

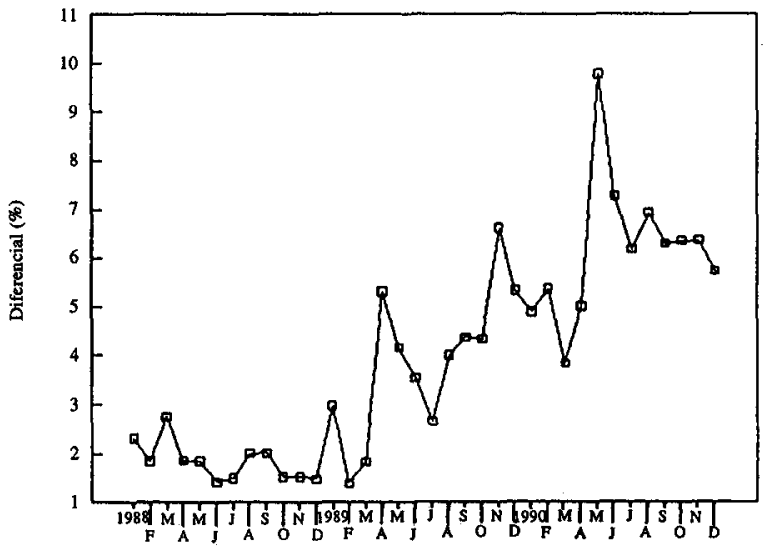

\section{Necesidad de coordinar la integración}

La sección anterior ha puesto de relieve la necesidad de establecer un marco de coordinación de políticas que permita eliminar los costos de una integración de hecho. A fin de aprovechar plenamente los beneficios de la integración, los países centroamericanos deberían adoptar un sistema de coordinación de políticas más general en el contexto de la armonización de la reforma estructural.

\footnotetext{
7 Sobre la coordinación de políticas en Centroamérica, véase la excelente síntesis de López (1994).
} 
c) Transformación estructural subregional

El tercer componente de la reforma es la transformación estructural. Los programas que los países decidieran impulsar al respecto en forma conjunta -políticas tecnológicas, apoyo a la innovación, desarrollo de las regiones más deprimidas (sobre todo de las zonas fronterizas) y diversificación de las relaciones económicas internacionales- se fortalecerían con la aplicación de un enfoque subregional, particularmente por el mayor acceso a recursos financieros y de cooperación técnica, y por la mayor coherencia de las políticas en el marco de la integración. Por otra parte, el enfoque subregional sería valioso para los gobiernos en su tarea de atender a los desequilibrios sociales. Esto también serviría como "efecto demostración", por lo cual procedería establecer una agenda subregional de reforma social que programara las acciones requeridas para nivelar de manera convergente el desarrollo social en la subregión, particularmente en educación básica, salud primaria y saneamiento. El gráfico 11 muestra, a manera de ejemplo, cómo se podría establecer una agenda subregional de reforma estructural a partir de los programas nacionales.

El mecanismo para establecer dicha agenda sería el Gabinete de Ministros Centroamericanos, el cual se reúne periódicamente para analizar asuntos de alcance subregional. En esas oportunidades se identificarían, para el sector de que se trate, los distintos aspectos que se cubrirían, diferenciando entre los de alcance nacional y los de repercusión subregional. El análisis de estos últimos tendría por objeto hacer a los países verdaderamente "integrables", asegurándose de que constituyan elementos congruentes de una matriz productiva centroamericana. Este enfoque también permitiría armonizar aquellos aspectos necesarios para la integración con el resto del mundo como un bloque.

\section{V Conclusiones}

La integración económica ofrece beneficios potenciales a los países centroamericanos porque puede estimular el crecimiento económico, la industrialización (por medio del comercio intraindustrial) y la eficiencia del aparato productivo (por la mayor competencia monopolística de carácter subregional y, particularmente, por garantizar el acceso a otros mercados). Estos beneficios constituyen una mejor base para enfrentar la competencia global derivada de la apertura externa. Pero el aprovechamiento de las posibilidades que ofrece la integración depende en gran parte de lo que hagan los países por reforzar su capital humano.

La integración también tiene costos, por las repercusiones imprevistas que las políticas monetarias y fiscales de un país ejercen sobre los otros, especialmente a través de la sustitución de monedas, lo cual restaría precisión a la programación monetaria nacional. El costo que emana de la integración monetaria de hecho sería eliminado por el "costo" de establecer un marco de coordinación que podría mermar la autonomía de las autoridades nacionales en la conducción de sus políticas macroeconómicas.

Los países centroamericanos deberían tomar ventaja del enfoque subregional en el proceso de reforma estructural, particularmente en materia social y reconversión industrial. Para que la reforma favorezca e impulse la integración subregional y sea congruente con ella, el proceso debería llevarse adelante según objetivos coincidentes y un calendario establecido, que podría ser diferente para cada país. Es conveniente entonces delinear una agenda subregional de reforma estructural que promueva el avance de todos los países y que impulse la integración con mayor coherencia y armonía tanto institucionales como sectoriales. La aplicación de esta agenda permitiría identificar oportunidades de complementación económica y de integración intersectorial y promovería la integración armónica con otras regiones. 


\section{Bibliografía}

Balassa, Bela (1966): Tariff reductions and trade in manufacturers among the industrial countries, The American Economic Review, vol. LVI, $\mathrm{N}^{\circ} 3$, Nashville, Tennessee, American Economic Association.

(1967): Trade creation and trade diversion in the European Common Market, Economic Journal, vol. LXXVII $\mathrm{N}^{\circ}$ 305, Londres, Macmillan (Journals) Limited, marzo.

(1979): Intra-industry trade and the integration of developing countries in the world economy, $\mathrm{H}$. Giersch (ed.), On the Economics of Intra-Industry Trade, Tübingen, J.C.B. Mohr.

Balassa, Bela y Luc Bauwens, (1987): Intra-industry specialization in a multi-country and multi-industry framework, The Economic Journal, vol. 97, $\mathrm{N}^{\circ} 388$, Oxford, Reino Unido, Basil Blackwell/Royal Economic Society, diciembre.

(1988): Inter-industry and intra-industry specialization in manufactured goods, Weltwirtschaftliches Archiv, Band 124.

Banco Mundial (1991): Informe sobre el desarrollo mundial 1991, Washington; D.C.

Begg, Ian y D. Mayes (1993): Cohesion, convergence and economic and monetary union in Europe, Regional Studies, vol. 27, Oxford, Reino Unido, Regional Studies Association, marzo.

Bulmer-Thomas, Victor (1992a): Regional integration and trade in manufactured goods, Miami, Estados Unidos, University of Miami, Graduate School of International Studies, mimeo.

(1992b): Regional integration in Central America: Impact of free trade in basic grains, Miami, University of Miami, Graduate School of International Studies, mimeo.

Cáceres, Luis René (1981): Integración económica y subdesarrollo en Centroamérica, México, D.F., Fondo de Cultura Económica.

Cáceres, Luis René y Salvador Quintanilla (1990): Sector externo y ahorro doméstico: el papel de las exportaciones intrarregionales en Centroamérica, Cuadernos de economía y finanzas, $\mathrm{N}^{\circ} 11$, Tegucigalpa, Banco Centroamericano de Integración Económica, (BCIE), abril.

Cáceres, Luis René y Oscar Núñez-Sandoval (1992): La relación de equilibrio de largo plazo entre los tipos de cambio en los mercados negros de Guatemala y El Salvador, El Trimestre Económico, Vol. LIX, No 235, México, D.F., Fondo de Cultura Económica, julio-septiembre.

Cáceres, Luis René y Stephen Seninger (1980): Endogenous change in an interegional system of growth centers: An application to the Central American Common Market, Regional Studies, vol. 14, Oxford, Reino Unido, Regional Studies Association, enero.

Cáceres, Luis René y José Roberto Suay (1988a): La sustitución entre las monedas de El Salvador y Guatemala, Cuadernos de Economía y Finanzas, $\mathrm{N}^{\circ} 4$, Tegucigalpa, D.C., BCIE, Departamento de Planificación, enero.

(1988b): La sustitución de monedas en El Salvador, Revista de la integración y el desarrollo de Centroamérica, $\mathrm{N}^{\circ}$ 43, Tegucigalpa D.C., BCIE, julio-diciembre.

CEPAL (Comisión Económica para América Latina y el Caribe) (1993): Evolución de la integración centroamericana en 1992. (LC/MEX/L.225), México D.F., Sede Subregional de la CEPAL en México.

Cline, William R. (1978): Benefits and costs of economic integration in Central America, William R. Cline y Enrique Delgado (eds.), Economic Integration in Central America, Washington, D.C., The Brookings Institution.

De Franco, Mario (1993): Evaluación y recomendaciones sobre la nueva integración centroamericana: un enfoque de equilibrio general, Managua, Instituto Centroamericano de Administración de Empresas (INCAE), diciembre.
Dowrick, Steve y Ducotho Nguyen (1989): OECD comparative economic growth 1950-1985: Catch-up and convergence, The American Economic Review, vol. LXXIX, No 2, Nashville, Tennessee, American Economic Association, diciembre.

FMI (Fondo Monetario Internacional) (1993a): Estadísticas financieras internacionales. Anuario 1993, vol. XLVI, Washington DC.

(1993b): Direction of Trade Statistics Yearbook, 1993, Washington, D.C.

Gallardo, Eugenia (1992): Centroamérica: La integración en los noventa: costos de la no integración, Miami, Estados Unidos, University of Miami, Graduate School of International Studies, mimeo.

Glejser, Herbert, Alexis Jacquemin y Jean Petit (1980): Exports in an imperfect competition framework: an analysis of 1446 exporters, The Quarterly Journal of Economics, vol. XCIV, $\mathrm{N}^{\mathrm{o}}$ 3, Nueva York, John Wiley \& Sons, mayo.

Gray, H. Peter (1988): Intra-industry trade: An "untidy" phenomenon, Weltwirtschaftliches Archiv, Band 124, Heft 2, Tübingen, J.C.B. Mohr.

Greenaway, David (1987): Inter-industry trade, inter-firm trade and european integration: evidence, gains and policy aspects, Journal of Common Market Studies, vol XXVI, $\mathrm{N}^{\circ}$ 2, Oxford, Reino Unido, Basil Blackwell Ltd., diciembre.

Greenaway, David y Chris Milner (1990): South-south trade, theory, evidence and policy, The World Bank Research Observer, vol. 5, $\mathrm{N}^{\circ}$ 1, Washington, D.C., Banco Mundial, enero.

Grubel H.G. y P.J. Lloyd (1975): Intra-Industry Trade, Londres, Macmillan.

Helpman, Elhanan y Paul R. Krugman (1986): Market Structure and Foreign Trade, Cambridge, Mass., The MIT Press.

Laird, Samuel (1981). Intra-industry trade and the expansion, diversification and integration of the trade of the developing countries, Trade and Development. An UNCTAD Review, $\mathrm{N}^{\circ}$ 3, Nueva York, Naciones Unidas, invierno. Publicación de las Naciones Unidas, $\mathrm{N}^{\circ}$ de venta E.82.II.D.3.

Laumas, Prem (1982): Exports and the propensity to save, Economic Development and Cultural Change, vol. 30, $\mathrm{N}^{\circ} 4$, Chicago Ill, University of Chicago Press.

Lee, Joong-Kong (1971): Exports and propensity to Save in L.D.C's, The Economic Journal, vol. 81, $\mathrm{N}^{\circ} 322$, Londres, Macmillan (Journals) Limited, junio.

Lee, Norman (1984): Business concentration in L.D.C's, C. H. Kirkpatrick, N. Lee y F. I. Nixson (eds.), Industrial Structure and Policy in Less Developed Countries, Londres, George Allen and Unwin.

(1992): Market structure and trade in developing countries, Gerald K. Helleinen, (ed.), Trade Policy, Industrialization, and Development, Oxford, Reino Unido, Claredon Press.

López, José Roberto (1994): Informe sobre la coordinación de políticas macroeconómicas en Centroamérica, San José, Costa Rica, Consejo Monetario Centroamericano (CMCA), Secretaría Ejecutiva.

Meller, Patricio (1978): The pattern of industrial concentration in Latin America, The Journal of Industrial Economics, vol. XXVI, $\mathrm{N}^{\circ}$ 1, Oxford, Reino Unido, Basil Blackwell, septiembre.

Neven, Damien J. y Lars-Hendrik Roller (1991): European integration and trade flows, European Economic Review, vol. 35, Amsterdam, North-Holland, mayo.

Nugent, Jeffrey (1974): Economic Integration in Central America, Baltimore, The Johns Hopkins University Press.

Rapoport, Alan I. (1978): Industrial structure in Central America, William R. Cline y E. Delgado, (eds.), Economic Integration in Central America, Washington D.C., The Brookings Institution. 
Rodrik, Dani (1988): Imperfect competition, scale economies, and trade policy in developing countries, Robert E. Baldwin, (ed.), Trade Policy Issues and Empirical Analysis, Chicago, Ill., The University of Chicago Press.

(1990): Trade Policies and Development: Some New Issues, Discussion paper, $N^{\circ} 447$, Londres, Centre for Economic Policy Research, agosto.

SIECA (Secretaría Permanente del Tratado General de Integración Económica Centroamericana) (varios números): Estadísticas Macroeconómicas de Centroamérica, Guatemala.
Smith, Alasdair y Anthony J. Venables (1988): Completing the internal market in the European Community, European Economic Review, vol. 32, Amsterdam, North-Holland, septiembre.

Webb, Michael y James Feckler (1993): Learning and the time interdependence of Costa Rican exports, Journal of Development Economics, vol. 40, $\mathrm{N}^{\circ} 2$, Amsterdam, North-Holland, abril.

Willmore, Larry y Jorge Máttar (1991): Reconversión industrial, apertura comercial y papel del Estado en Centroamérica, $R e$ vista de la CEPAL, $\mathrm{N}^{\circ} 44$ (LC/G. 1667-P), Santiago de Chile, Naciones Unidas, agosto. 